\title{
Effects of BRCA2 cis-regulation in normal breast and cancer risk amongst BRCA2 mutation carriers
}

\author{
Ana-Teresa Maia ${ }^{1,2,30^{*}}$, Antonis C Antoniou ${ }^{3}$, Martin O'Reilly', Shamith Samarajiwa ${ }^{1,2}$, Mark Dunning ${ }^{1}$, \\ Christiana Kartsonaki ${ }^{3}$, Suet-Feung Chin ${ }^{1,2}$, Christina N Curtis ${ }^{1,2,29}$, Lesley McGuffog ${ }^{3}$, Susan M Domchek ${ }^{4}$, \\ EMBRACE ${ }^{3}$, Douglas F Easton ${ }^{3}$, Susan Peock ${ }^{3}$, Debra Frost ${ }^{3}$, D Gareth Evans ${ }^{5}$, Ros Eeles ${ }^{6}$, Louise Izatt $^{7}$, \\ Julian Adlard ${ }^{8}$, Diana Eccles ${ }^{9}$, GEMO Study Collaborators ${ }^{10}$, Olga M Sinilnikova ${ }^{11,12}$, Sylvie Mazoyer ${ }^{11}$,

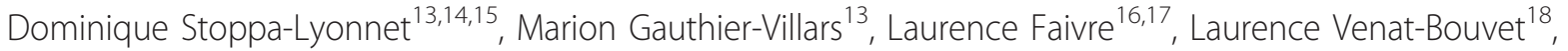 \\ Capucine Delnatte ${ }^{19}$, Heli Nevanlinna ${ }^{20}$, Fergus J Couch ${ }^{21}$, Andrew K Godwin ${ }^{22}$, Maria Adelaide Caligo ${ }^{23}$, \\ SWE-BRCA, Rosa B Barkardottir ${ }^{24,25}$, kConFab Investigators ${ }^{26}$, Xiaoqing Chen ${ }^{27}$, Jonathan Beesley ${ }^{27}$, Sue Healey ${ }^{27}$, \\ Carlos Caldas ${ }^{1,2,28}$, Georgia Chenevix-Trench ${ }^{27}$ and Bruce AJ Ponder ${ }^{1,2}$
}

\begin{abstract}
Introduction: Cis-acting regulatory single nucleotide polymorphisms (SNPs) at specific loci may modulate penetrance of germline mutations at the same loci by introducing different levels of expression of the wild-type allele. We have previously reported that BRCA2 shows differential allelic expression and we hypothesize that the known variable penetrance of BRCA2 mutations might be associated with this mechanism.

Methods: We combined haplotype analysis and differential allelic expression of BRCA2 in breast tissue to identify expression haplotypes and candidate cis-regulatory variants. These candidate variants underwent selection based on in silico predictions for regulatory potential and disruption of transcription factor binding, and were functionally analyzed in vitro and in vivo in normal and breast cancer cell lines. SNPs tagging the expression haplotypes were correlated with the total expression of several genes in breast tissue measured by Taqman and microarray technologies. The effect of the expression haplotypes on breast cancer risk in BRCA2 mutation carriers was investigated in 2,754 carriers.
\end{abstract}

Results: We identified common haplotypes associated with differences in the levels of BRCA2 expression in human breast cells. We characterized three cis-regulatory SNPs located at the promoter and two intronic regulatory elements which affect the binding of the transcription factors C/EBP $\alpha, H M G A 1$, D-binding protein (DBP) and ZF5. We showed that the expression haplotypes also correlated with changes in the expression of other genes in normal breast. Furthermore, there was suggestive evidence that the minor allele of SNP rs4942440, which is associated with higher BRCA2 expression, is also associated with a reduced risk of breast cancer (per-allele hazard ratio $(H R)=0.85,95 \%$ confidence interval $(C l)=0.72$ to $1.00, P$-trend $=0.048)$.

Conclusions: Our work provides further insights into the role of cis-regulatory variation in the penetrance of disease-causing mutations. We identified small-effect genetic variants associated with allelic expression differences in BRCA2 which could possibly affect the risk in mutation carriers through altering expression levels of the wildtype allele.

\footnotetext{
* Correspondence: atm29@cam.ac.uk

${ }^{1}$ Cambridge Research Institute - CRUK, Li Ka Shing Centre, Cancer Research

UK, Robinson Way, Cambridge, CB2 ORE, UK

Full list of author information is available at the end of the article
} 


\section{Introduction}

Unequal expression of the alleles of autosomal genes is common in the human genome [1,2]. This differential allelic expression (DAE) is thought to play a major role in intra-species phenotypic variation as well as individual susceptibility to complex diseases. Previous reports have suggested a role for DAE in cancer, including that of the colon [3,4], the pancreas [5], the ovary [6] and the breast $[7,8]$. Additionally, several cancer risk-associated SNPs identified through genome-wide association studies (GWAS) have been shown to have a role in gene expression regulation [9-13]. We previously reported that BRCA2 displays DAE in breast and blood samples from healthy individuals [14]. Using a coding single nucleotide polymorphism (SNP) in exon 9 of $B R C A 2$, rs144848, as a marker for quantifying allelic transcripts in heterozygous individuals, we observed differences between alleles as large as four-fold. Additionally, our data suggested that the cis-regulatory variation responsible for DAE is in the same haplotype block as rs144848.

Deleterious germline mutations in $B R C A 2$ are rare but confer a high risk of breast cancer. However, penetrance estimates vary and several lines of evidence indicate that other genetic and environmental factors modify the cancer risks conferred by these mutations [15-17]. Studies by the Consortium of Investigators of Modifiers of $B R C A 1 / 2$ (CIMBA) have demonstrated that common alleles in RAD51, FGFR2, MAP3K1, TOX3/TNRC9, LSP1, SLC4A7/NEK10, a 2q35 locus and a 5p12 locus affect breast cancer risk in BRCA2 mutation carriers [18-20]. These loci account for approximately $4 \%$ of the genetic variation observed in the penetrance of $B R C A 2$ mutations in breast cancer.

Most of the deleterious germline mutations in BRCA2 introduce premature termination codons and trigger nonsense-mediated mRNA decay [11]. Haploinsufficiency in $B R C A 2^{+/-}$cells has been shown to affect DNA damage repair of breaks induced by $\gamma$-irradiation and mitomycin C [21] which can contribute to cancer predisposition in mutation carrier families. Recently, it was also reported that primary breast epithelial cells cultured from $B R C A 2$ mutation carriers and controls have differences in gene expression signatures [22].

In this study, we set out to identify and characterize cisregulatory variation responsible for DAE in $B R C A 2$ and to determine whether the penetrance of $B R C A 2$ mutations could be modified by the variable level of expression of the remaining wild-type allele in heterozygous mutation carriers. We identified common haplotypes that associate with different levels of BRCA2 expression and found three SNPs that alter the binding affinity of transcription factors and overlap cis-regulatory elements. The expression haplotypes were also found to correlate with altered expression in breast tissue of genes whose expression has previously been reported to be altered in the presence of inherited $B R C A 2$ mutations. We found one haplotype that was associated with higher expression of $B R C A 2$, for which there is suggestive evidence that it is also associated with a protective effect for the development of breast cancer in $B R C A 2$ mutation carriers.

\section{Materials and methods \\ SNP and haplotype analysis}

Hapmap release 16 and data from the 1,000 Genomes Project were accessed [23-26]. Haplotype structure and linkage disequilibrium analysis were performed using Haploview software [27,28].

\section{Human tissue samples}

$\mathrm{B}$ cells and normal breast tissue from healthy individuals and normal matched breast tissue from cancer patients were obtained from the Blood Centre and the Tissue Bank at Addenbrooke's Hospital as previously described [14], with approval from the Addenbrooke's Hospital Local Research Ethics Committee (REC reference 04/ Q0108/21, 06/Q0108/221 and 07/H0308/161, respectively). The $\mathrm{B}$ cell and control normal breast tissue material was used for the functional analysis and the DAE study. The normal matched breast tissue was used for total gene expression studies.

\section{Nucleic acid extraction and processing}

DNA was extracted using a conventional SDS/proteinase $\mathrm{K} /$ phenol method. Total RNA was extracted from all samples using Qiazol (QIAGEN, Crawley, UK) following the manufacturer's instructions. The RNA was subsequently treated with DNaseI and repurified using acidic phenol-chloroform, and ethanol precipitation. DNA and RNA integrity were checked using the Agilent Bioanalyzer (Agilent Technologies, Santa Clara, CA, USA).

cDNA was prepared from total RNA with the SuperScript ${ }^{\circledR}$ III First Strand SuperMix (Invitrogen, Carlsbad, CA, USA) using random hexamers and oligo-dT primers, according to the manufacturer's instructions.

\section{Breast cell lines culture}

Breast cancer (PMC42, MCF-7 and SUM-159) and normal breast (MCF-10A) cell lines were cultured as previously described [29-32] for extracting nuclear protein for electrophoretic mobility shift assays and for extracting chromatin for immunoprecipitation assays.

\section{Genotyping of normal blood and breast tissue from healthy individuals}

Genotyping for rs144848 was performed using a fluorescent 5' exonuclease TaqMan assay and the ABI PRISM 
7900 Sequence Detection Sequence (Applied Biosystems, Foster City, CA, USA). Genotyping for another six SNPs that tag common haplotypes for the DAE region in BRCA2 was carried out by PCR amplification of $150 \mathrm{bp}$ to $250 \mathrm{bp}$ around the SNP of interest. Primer sequences are provided in the Supplementary Material (Additional file 1 Table S1). Products were verified by agarose gel electrophoresis and sequenced using ABI Big Dye chemistry and capillary electrophoresis on an ABI 3730 sequencer (Applied Biosystems).

\section{Affymetrix Genotyping}

Thirty-seven normal breast tissue samples were genotyped using Affymetrix Genome-Wide SNP 6.0 arrays (Affymetrix, Santa Clara, CA, USA), following the standard Affymetrix protocol using $0.5 \mu \mathrm{g}$ DNA, at AROS Applied Biotechnology (Aarhus, Denmark). Affymetrix SNP 6.0 arrays data were pre-processed and analyzed using the crlmm Bioconductor package [33] implemented in the $\mathrm{R}$ statistical programming language [34] (GEO: GSE32259).

\section{Quantification of differential allelic gene expression}

Differential allelic expression assays were performed as previously described [14]. Validation was performed by Sanger sequencing. In brief, replicate PCRs were performed amplifying $100 \mathrm{bp}$ to $200 \mathrm{bp}$ around the coding SNP of interest; products were verified by agarose gel electrophoresis and sequenced using ABI Big Dye chemistry and capillary electrophoresis on an ABI 3730 sequencer (Applied Biosystems). Allelic expression ratios in cDNA samples were normalized against the genomic DNA ratios. Primer sequences are provided as Supplementary Material (Additional file 1 Table S1).

\section{In silico prediction of transcription factor binding}

TRANSFAC professional database [35] (Biobase, Germany) ver.2009.4 with vertebrate non redundant matrices, and MATCH algorithm with core match and matrix match set to minimize the sum of both false positives and negative motif matches were used to identify putative transcription factor binding sites.

\section{Electrophoretic mobility shift assay (EMSA)}

EMSA were performed as previously described [9]. Each EMSA was repeated two or more times for all combinations of cell extract and oligonucleotide, which were also tested in serial diluting amounts. Oligonucleotide sequences are provided as Supplementary Material (Additional file 1 Table S1). Antibodies used for supershift competition assays are listed in the Chromatin Immunoprecipitation section.

\section{Chromatin Immunoprecipitation (ChIP)}

ChIP experiments were performed using chromatin extracted from SUM-159 (cancer), PMC42 (cancer), MCF-7 (cancer) and MCF10-A (normal) breast cell lines with antibodies against RNA polymerase II (Abcam, Cambridge, UK, ab5408-100), H3K79me2 (Abcam, ab3594), HMGA1a/HMGA1b (Abcam, ab4078), DABP (Insight Biotechnology Ltd, Wembley, UK, sc-98411-X), ZFP161 (Abcam, ab68116), C/EBPa (Insight Biotechnology Ltd, sc-9314-X), IgG-Rabbit (Insight Biotechnology Ltd, sc-2027) and IgG Mouse (Insight Biotechnology Ltd, sc-2025) as recently described [36]. The immunoprecipitated material was purified using QIAquick PCR Cleaning kit (Qiagen) and analyzed by PCR for the regions of interest. Primer sequences are supplied in the Supplementary Material (Additional file 1 Table S1).

\section{Gene Expression Analysis}

The relative gene expression of BRCA2, SPP1, MUC16, $P A X 8, B I R C 5$ and RRM2 was analyzed using Fluidigm 96.96 Dynamic Arrays (Fluidigm, San Francisco, CA, USA), according to the manufacturer's instructions, in a set of normal breast tissue from healthy donors $(\mathrm{n}=$ 58). Four housekeeping genes (Actin $\beta, H P R T 1,18 S$ and $G A P D H)$ were included in the experiments for normalization purposes.

In short, $1.25 \mu \mathrm{L}$ of cDNA was pre-amplified in a $5 \mu \mathrm{L}$ reaction for the specific targets $(0.2 \mathrm{x}$ of each assay), for eight cycles. Pre-amplified samples were diluted 1:5 before being utilized. Chips were run on the BioMark ${ }^{\mathrm{TM}}$ Real-Time PCR System (Fluidigm). The cycling program used consisted of 10 minutes at $95^{\circ} \mathrm{C}$ followed by 40 cycles of $95^{\circ} \mathrm{C}$ for 15 seconds and one minute at $60^{\circ} \mathrm{C}$. Data were analyzed using the BioMark Gene Expression Data Analysis software to obtain Ct values. Each chip (experiment) was run with all assays plated in triplicate and 94 test samples plus two no-template control samples. Analysis was performed using the $\Delta \Delta \mathrm{Ct}$ method and normalization was done using the average $C t$ value for the two housekeeping genes (Actin $\beta$ and HPRT1) that had the most similar distribution of $\mathrm{Ct}$ values across arrays.

Additionally, we analyzed separately 33 normal breast tissue samples from healthy individuals and 200 normal breast tissue samples from cancer patients (normalmatched) without BRCA2 germline mutations, using Illumina HT12 v3 expression arrays (Illumina, San Diego, CA, USA) (GEO: GSE32259 and EGA: EGAS00000000082). Briefly, for each sample set the bead array package [37] was employed to pre-process and summarize each Illumina H12 v3 BeadChip following quality assessment and the adjustment of spatial artefacts with the BASH tool [38]. Potential outlier 
arrays were removed by considering the bead-level quality assurance (QA) scores derived using the control probes on each array and the remaining samples were quantile normalized.

\section{Gene expression statistical analysis}

All statistical analysis was performed using $\mathrm{R}$ version 2.10.1 [34], unless otherwise stated. Differential allelic expression data were analyzed as previously described [14]. Comparison of proportions between groups for haplotype correlation with DAE was tested using the Chi-square test. The non-parametric Wilcoxon rank sum test was used for the analysis of BRCA2 expression versus haplotype. Specific SNP genotype-gene expression correlations were determined using analysis of variance (ANOVA) testing for the first type of correlation and the Student's t test for the second.

\section{Associations with breast cancer risk for BRCA2 mutation carriers}

Associations with breast cancer risk were evaluated using women with $B R C A 2$ mutations from 11 studies from the CIMBA consortium for the seven SNPs defining the gene expression associated haplotypes. Subjects participated in clinical or research studies at the host institutions under ethically approved protocols and written informed consent was obtained (Additional file 2 Table S2).

Studies included per SNP in our analysis are shown in Additional file 3 (Table S3). Sample eligibility and available information were reported in detail previously and are provided in Additional file 4[39]. The DNA samples of ten studies were genotyped by iPLEX Mass Array platform (Sequenom Inc., Newton, MA, USA) at Queensland Institute of Medical Research, with a further study, GEMO, genotyped elsewhere by Taqman assay, using Applied Biosystems reagents (Applied Biosystems), for the same seven SNPs. Further details on the genotyping and quality control are described in Additional file 4 .

Details of the statistical analysis methods for evaluating the associations between SNP genotypes and breast cancer risk have been published previously and are provided in Additional file 4[18]. In short, we tested the frequency of each SNP in affected (cases) and unaffected (control) BRCA2 germline mutation carriers. The effect of each SNP was modelled either as a per-allele HR (multiplicative model) or as separate HRs for heterozygotes and homozygotes, and these were estimated on the log scale. Analyses were carried out with the pedigree-analysis software MENDEL [40]. Heterogeneity between studies was tested by comparing the models that allowed for study-specific log-HRs against models in which the same log-HR was assumed to apply to all studies.

Disease associations for the five common expression haplotypes were also explored using the software HAPSTAT [41], under a standard cohort analysis model and using the low expression haplotype 2 as the reference. It should be noted that this analysis does not account for the sampling design and familial relationships of the participating studies.

\section{Results}

\section{Haplotype correlation with levels of expression}

Recently, we reported differential allelic expression of $B R C A 2$ in both normal breast and blood tissue samples from control individuals [14]. Using the coding SNP rs144848 for allelic transcript quantification and an allelic expression ratio threshold of $1.2\left(\log _{2}=0.263\right)$, we found that in 45 heterozygous samples tested 29 (64\%) significantly expressed more of the $\mathrm{G}$ allele. All heterozygotes showing DAE preferentially expressed the same allele, indicating that the coding SNP rs144848 is in linkage disequilibrium (LD) with the regulatory variant (s). Linkage disequilibrium is however not complete between the coding and the regulatory $\mathrm{SNP}(\mathrm{s})$ as suggested by the fraction of heterozygotes that did not show DAE, who are likely homozygous for the regulatory variant(s).

In this study, for the identification of possible cis-regulatory polymorphisms we first analyzed the region surrounding $B R C A 2$, which shows very complex linkage disequilibrium. Using data from HapMap (Data release 24/phase II, dbSNP build 126) and the Haploview software, we identified three main haplotype blocks with two further regions without clear block structure, corresponding to five common haplotypes in the European population (CEU samples in HapMap) (tag SNPs for the haplotypes are shown in Table 1$)$. The $G$ allele of the coding SNP rs144848 tags one of these haplotypes, haplotype 1. As the samples used for the DAE study are all heterozygous for rs144848, all samples carry haplotype 1. To evaluate the association between the other haplotypes and the observed DAE we determined the second haplotype in 41 samples heterozygous for rs144848 used in the DAE study. For this we genotyped the samples for the six tag SNPs defining haplotypes 2/3/4/5 and correlated them with the presence or absence of DAE ('DAE' versus 'no DAE' in Table 1). All samples carrying haplotype 2 showed DAE (Sign Test $P$-value $=0.031$ ) and samples with haplotype 5 showed a non-significant predominance in the DAE group. Haplotypes 3 and 4 were found in equal frequency in individuals with and without DAE. Correlation of DAE ratios versus haplotype shows (Figure 1) that haplotypes 2 and 5 have, on 
Table 1 Haplotype frequencies in BRCA2, tag SNPs and DAE distribution

\begin{tabular}{|c|c|c|c|c|c|c|c|c|c|c|}
\hline $\begin{array}{l}\text { HAPLOTYPE } \\
\text { PATTERN }\end{array}$ & $\begin{array}{c}\text { Freq (\%) HapMap } \\
\text { CEU }\end{array}$ & rs1799943 & rs11571579 & rs9534174 & rs206070 & rs144848 & rs4942440 & rs9567576 & DAE & $\begin{array}{l}\text { No } \\
\text { DAE }\end{array}$ \\
\hline hap1 & 27.5 & G & T & A & $C$ & G & G & T & 29 & 12 \\
\hline hap2 & 24.2 & A & C & G & C & T & G & G & $10^{*}$ & $0^{*}$ \\
\hline hap3 & 18.8 & G & $\mathrm{T}$ & A & $\mathrm{T}$ & $\mathrm{T}$ & G & T & 4 & 4 \\
\hline hap4 & 11.7 & G & $\mathrm{T}$ & G & C & $\mathrm{T}$ & A & T & 10 & 7 \\
\hline hap5 & 5 & G & $C$ & G & C & T & G & G & 5 & 1 \\
\hline
\end{tabular}

* $P$-value $=0.031$, Sign-Test. CEU, Utah residents with Northern and Western European ancestry from the CEPH collection; DAE, differential allelic expression; SNP, single nucleotide polymorphism.

average, a larger difference in the allelic expression than haplotypes 3 and 4 , meaning that the $T$ allele of rs 144848 is less expressed than the G allele when it is inherited as haplotype 2 or 5 . In view of these results we defined haplotypes 2 and 5 as 'lower expression' and haplotypes 1, 3 and 4 as 'higher expression' haplotypes.

\section{Gene expression profile of breast tissue is dependent on haplotype}

Having identified different expression haplotypes for $B R C A 2$ we investigated whether these had an effect on the expression of the eleven genes reported to be altered by Bellacosa and colleagues [22] in BRCA2 mutation carriers. We measured the expression level of IGFBP5, SPP1, RRM2, BIRC5, MUC16 and PAX8 by quantitative real-time PCR and of all eleven genes using Illumina

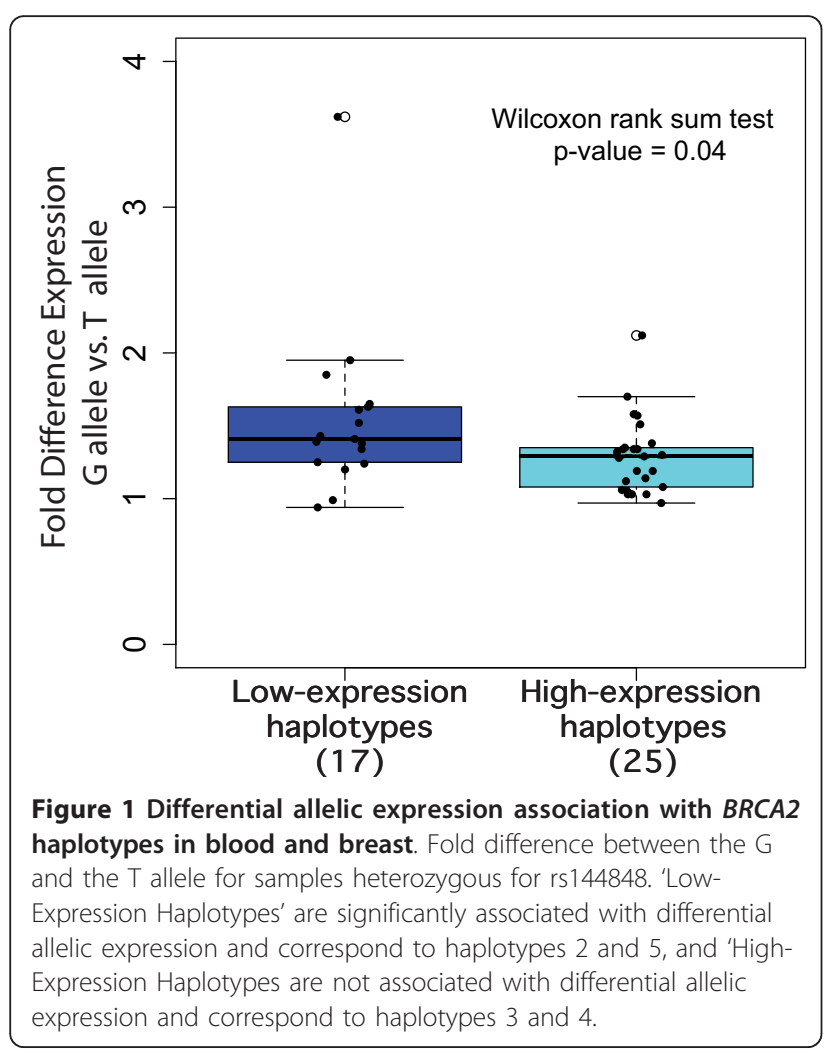

HT12 v3 expression microarrays in the normal breast tissue of healthy controls, in the normal breast tissue of breast cancer patients (non-carriers of BRCA2 germline mutations) and also in blood from healthy controls. We analyzed the results in two ways. The first consisted of correlating gene expression versus genotype at specific SNPs that tag different haplotypes, using a linear regression model and ANOVA analysis. In this analysis the heterozygous and the common homozygous groups consist of a mixture of high and low expression haplotypes. To reduce this noise in the data, in the second type of analysis we assigned samples to three groups: individuals carrying two high expression haplotypes, individuals carrying one high and one low expression haplotype, and individuals carrying two low expression haplotypes. We performed Student's t test analysis for the expression of each gene between each two groups. This approach implied a reduction in the number of informative samples. We found evidence of correlation between four out of eleven genes (SPP1, PAX8, MUC16 and IGFBP5) and the expression haplotypes (Figure 2) which we describe in detail below.

In normal breast tissue from healthy individuals, higher expression of SPP1 was found in cells homozygous for the rare allele of rs206081, an SNP in strong LD with the tag for the high-expression haplotype 3 ( $P$ value $=0.039$, Figure $2 \mathrm{~A}$ ). This correlation was in concordance with the expression haplotype analysis in blood of healthy individuals using real-time PCR data, in which expression of SPP1 was found to be significantly higher in individuals carrying two high expression haplotypes $(P$-value $=0.006$, difference expression $=1.74$, Figure $2 \mathrm{~B})$, when compared with individuals carrying one high and one low expression haplotype (no individuals were identified with two low expression haplotypes in these samples). This correlation was found to be in the opposite direction in the normal tissue of breast cancer patients, with lower SPP1 expression associated with a low $B R C A 2$ expression haplotype ( $P$-value $=0.038$, Figure $2 \mathrm{~A}$ ). The gene $P A X 8$ showed a concordant correlation in normal breast from healthy controls and cancer patients, showing upregulation in rare homozygous samples for SNPs that correspond to 


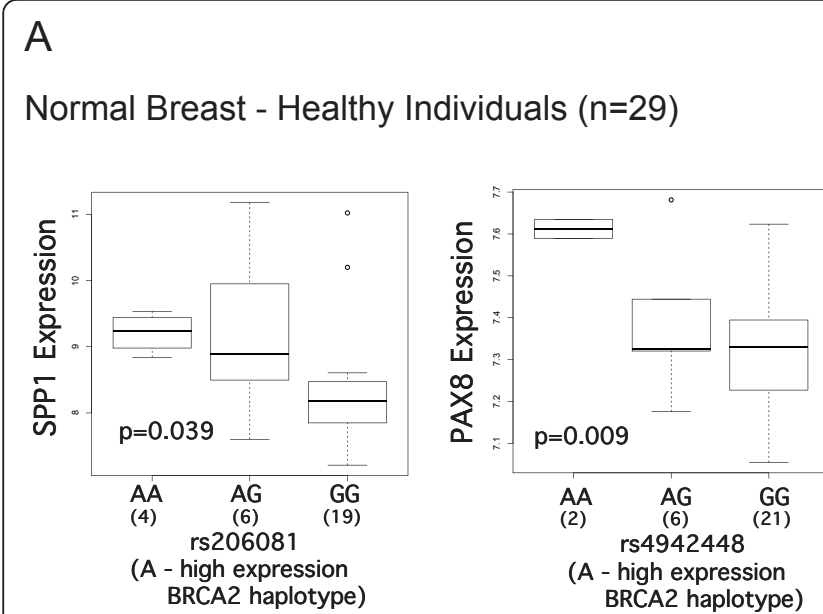

Normal Breast - Breast Cancer Patients $(n=144)$
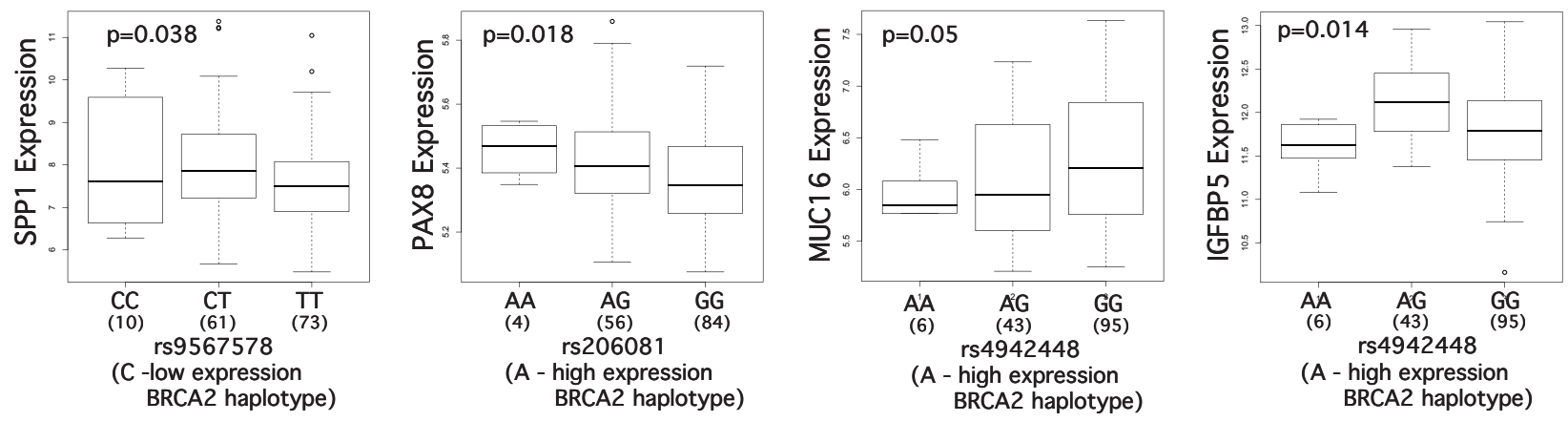

B

Blood -

Healthy Individuals $(n=20)$

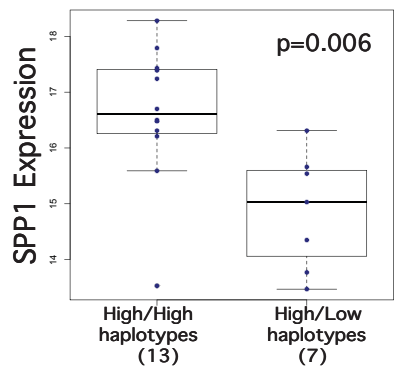

Normal Breast Breast Cancer patients $(n=144)$

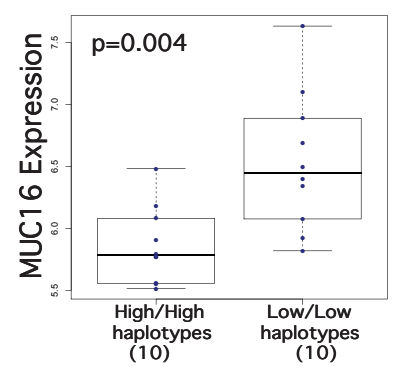

Figure 2 Differential gene expression analysis in normal breast tissue (controls and breast cancer patients) and normal blood samples. Box plots displaying differentially expressed genes in normal breast samples from healthy controls $(n=29)$, matched normal breast tissue from breast cancer patients $(n=144)$ and blood samples from healthy individuals $(n=20)$ analyzed by Illumina HT12 v3 arrays and real-time PCR. (A) Gene expression versus genotype correlations between the genes SPP1, PAX8, MUC16 and IGFBP5 and two SNPs associated with higher expression of BRCA2, rs206081 (haplotype 3) and rs4942448 (haplotype 4), and one SNP associated with lower expression of BRCA2, rs9567578 (haplotype 2); P-values correspond to ANOVA testing. (B) Gene expression versus expression haplotype correlations for the genes MUC16 and SPP1; P-values correspond to a two-sided Student's t-Test. ANOVA, analysis of variance; PCR, polymerase chain reaction; SNP, single nucleotide polymorphism. 
haplotypes 3 (rs206081) and 4 (rs4942448), both associated with higher expression of BRCA2 (P-value = 0.009 in healthy individuals, $P$-value $=0.018$ in cancer patients; Figure 2A). The expression of MUC16 in the normal tissue of patients was negatively correlated with the A allele of rs4942448 (haplotype 4$)(P$-value $=0.05$ in Figure 2A). The upregulation of MUC16 in individuals carrying two low-expression haplotypes was confirmed with the second analysis method ( $P$-values = 0.004 in Figure 2B). The difference in expression between the high-expression and low-expression haplotype groups was -0.125 for the two probes. In the normal tissue of patients, the expression of IGFBP5 was significantly lower in samples homozygous for rs4942448 (haplotype 4), which is associated with lower $B R C A 2$ expression $(P$-values $=0.014$, Figure $2 \mathrm{~A})$.

These results suggest that even small differences in the expression level of $B R C A 2$, as those associated with the different haplotypes that we identified, can have an impact on the gene expression profile of normal breast tissue in individuals carrying two copies of $B R C A 2$.

\section{Associations with breast cancer risk for BRCA2 mutation carriers}

The seven SNPs that characterize the five expression haplotypes identified in the DAE study were genotyped in 2,754 BRCA2 mutation carriers from 11 centers from the CIMBA consortium (Additional file 3 Table S3, Additional file 5 Table S4). In total, 1,617 carriers were censored at a first breast cancer diagnosis and 1,137 were treated as unaffected in the analysis. One SNP displayed a significant association with breast cancer in carriers of BRCA2 mutations (Table 2) at the 5\% significance level. The minor allele of SNP rs4942440, tagging the high expression haplotype 4, was associated with a reduced breast cancer risk (per-allele $\mathrm{HR}=0.85,95 \% \mathrm{C}$. I. $=0.72$ to $1.00, P$-trend $=0.048)$. There was no evidence of heterogeneity in the HRs across studies ( $P$-heterogeneity $=0.20$, Additional file 6 Figure S1). No associations were observed with the other SNPs (Additional file 5 Table S4). Similar to the gene expression analysis presented above, the association analysis based

Table 2 rs4942440 genotype frequencies in BRCA2 mutation carriers by disease status and hazard-ratio estimate

\begin{tabular}{lccccc}
\hline & Unaffected (\%) & Affected (\%) & HR & 95\% Cl & $P$ Value \\
\hline GG & $648(70.36)$ & $817(73.47)$ & 1 & & \\
AG & $246(26.71)$ & $271(24.37)$ & 0.84 & $(0.70,1.01)$ & \\
AA & $27(2.93)$ & $24(2.16)$ & 0.76 & $(0.43,1.36)$ & \\
2-df test & & & & & 0.13 \\
Per allele & & & 0.85 & $(0.72,1.00)$ & 0.048 \\
\hline
\end{tabular}

on each SNP in isolation does not describe the effects of each haplotype separately, as there is no distinction between low and high expression haplotypes in the heterozygous and common homozygous groups.

To address this fact we performed a haplotype analysis using standard cohort analysis in which the low-expression haplotypes 2 and 5 were considered as reference. This revealed that each copy of the higher-expression haplotype 4 was associated with a reduced risk of breast cancer for BRCA2 mutation carriers $(\mathrm{HR}=0.84,95 \% \mathrm{CI}$ : 0.73 to $0.97, P=0.014$ ) (Additional file 7 Table S5). However, this analysis does not take into account the non-random sampling of mutation carriers with respect to disease phenotype, or possible family relations within the individuals studied, so inference based on this analysis is not directly comparable with the single SNP analysis which was based on modelling the retrospective likelihood. Nevertheless, this is also suggestive of an association between a higher expression haplotype of $B R C A 2$ in mutation carriers with lower risk of developing breast cancer.

\section{Identification of regulatory variation}

Next we aimed to dissect the genetic cis-regulation responsible for the haplotype differences in the expression level of BRCA2. We performed a series of in silico, in vitro (Figure 3 ) and in vivo (Figure 4 ) experiments in human breast cells. Twenty-six SNPs tagged by all five haplotypes were identified using Haploview and HapMap data. We used four criteria for selecting SNPs for further analyses. First, we selected the SNPs located inside regulatory elements described by the Ensembl database. Secondly, we selected the SNPs whose surrounding DNA sequence was predicted to potentially bind transcription factors (TF). For this purpose, $40 \mathrm{bps}$ of DNA sequence surrounding these SNPs were analyzed in silico using TRANSFAC and MATCH for determining likelihoods of these DNA sequences to bind TFs. We used a cut-off of 0.9 for the matrix and core similarity scores; these scores correspond to the quality of a match between the DNA sequence and the TF binding matrix and the core sequence of a matrix (the five most conserved consecutive positions in a matrix), respectively. Thirdly, the TF binding site needed to overlap the SNP location. Finally, there had to be a difference between alleles in terms of presence/absence of binding and differences in scores between alleles.

The tag SNP specific for haplotype 2, rs1799943 (Functional SNP 1 in Figure 5), and another in complete LD (rs9567552) were the only SNPs localized at the promoter region of BRCA2. They map within a RNA polymerase II (PolII) binding site at the promoter region of $B R C A 2$. To confirm binding at the promoter site we performed ChIP using RNA PolII-specific and 


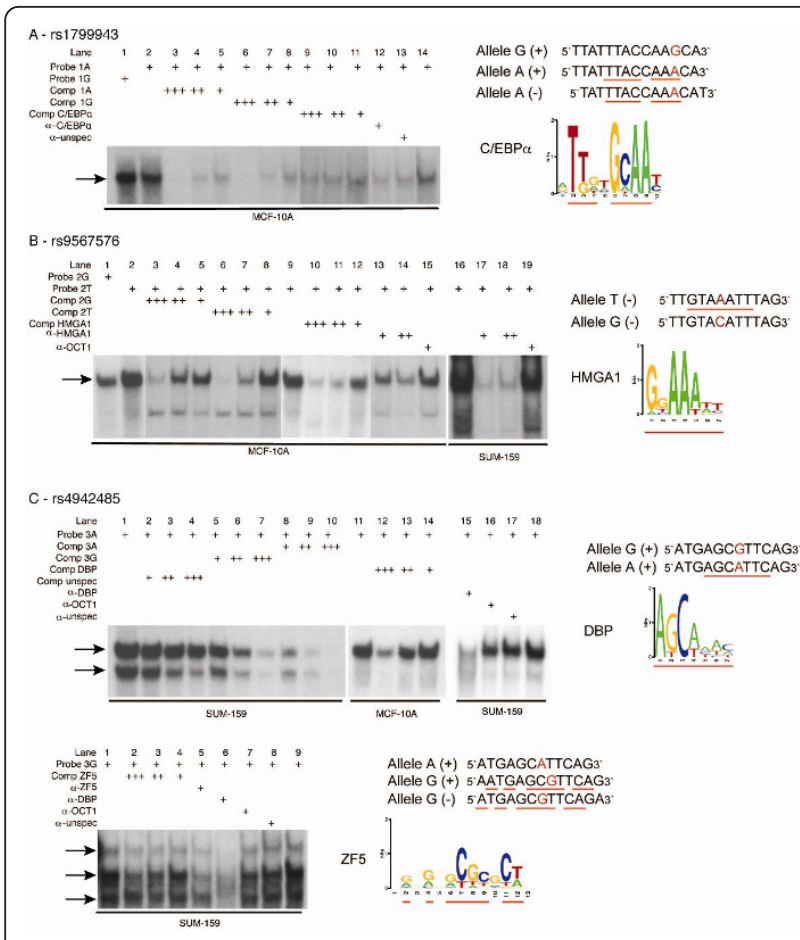

Figure 3 In silico and in vitro DNA-protein binding studies. EMSA results, binding sequence motifs for each transcription factor and the DNA sequence around each SNP (alleles in red) are shown. Sequences are shown in the strand direction for which the prediction was found, and red underlines indicate homology between TF motif and allele sequence. DNA motifs were obtained from TRANSFAC and Schmidt et al. (C/EBP $\alpha)$ [12,50]. Arrows indicate specific bands for each EMSA. (A) Both alleles of rs1799943 show weak in vitro binding of C/EBP $\alpha$. (B) Analysis of rs9567576, using cell extract from two cell lines as indicated, and competition assays indicate stronger binding of HMGA1 to the probe containing the $T$ allele. (C) EMSA analysis of rs4942485 for the A allele (upper panel) and $\mathrm{G}$ allele (lower panel). The A allele shows strong binding to DBP, as identified by competition assays. When using the probe containing the $\mathrm{G}$ allele, a lower third band appears in the presence of $\mathrm{Zn}^{2+}$ in the buffer, identified as binding to ZF5 in competition assays. EMSA, electrophoretic mobility shift assay; DBP, d-binding protein; SNP, single nucleotide polymorphism; TF, transcription factors.

H3K79me2-specific antibodies (a histone modification commonly associated with transcription elongation [42]) and verified occupancy at the site of these variants (Additional file 8 Figure S2). In silico analysis (Additional file 9 Table S6) suggested that the DNA sequence surrounding this polymorphism could bind OCT-1 with both alleles and also C/EBP $\alpha$, but only in the minor $\mathrm{A}$ allele form. EMSAs showed that in vitro both alleles had the ability to bind C/EBP $\alpha$ Figure 3A. Next, through ChIP analysis using specific antibodies against OCT-1 and $C / E B P \alpha$, we found the site to be occupied in vivo by $\mathrm{C} / \mathrm{EBP} \alpha$, in two breast cancer cell lines (Figure $4 \mathrm{~A}$ ). The pull-down was significantly higher for C/EBP $\alpha$ in a heterozygous cell line compared to another homozygous for the G allele (Student's t test $P$-value $=0.03$ ). No occupancy was verified for the rs9567552 site.

Three other SNPs passed our selection criteria for analysis by EMSA to evaluate binding of the predicted TFs in vitro, using nuclear protein extracts from two breast cancer and one normal cell line. Two of these three SNPs showed the ability to bind in vitro in an allelic-preferential or allele-specific manner to the predicted TFs (Figure 3B and 3C) and were further characterized by ChIP analysis.

SNP rs9567576 (Functional SNP 2 in Figure 5), tagging haplotypes 2 and 5, located in a regulatory feature in intron 11, resides within a putative binding site for the high-mobility group protein HMGA1, with the T allele better matching the consensus sequence. The band observed in the EMSA experiment (Figure 3B) was consistently stronger for the $\mathrm{T}$ allele in replicate experiments, corroborating the in silico predictions, although the $G$ allele could still bind. In a competition EMSA experiment, an oligonucleotide centered on SNP rs9567576 competed more efficiently for binding when the SNP position was a $\mathrm{T}$ as compared to a G. Additionally, a consensus probe and a specific antibody against HMGA1 competed strongly for binding. The physical presence of HMGA1 at the rs9567576 site was demonstrated by site-specific ChIP analysis in both MCF-7 and MCF-10A cells (homozygous for the T allele and heterozygous at rs9567576, respectively) (Figure 4B). Although a stronger ChIP result was obtained for MCF$10 \mathrm{~A}$ cells (genotype TG), comparative sequencing of the immunoprecipitate and the input chromatin, showed that HMGA1 binds this site in the presence of both alleles but there is a preferential binding for the $\mathrm{T}$ allele (Figure 4B).

SNP rs4942485 (Functional SNP 3 in Figure 5), which is tagged by rs 4942440 and haplotype 4 , maps inside a regulatory feature in intron 20 . It was predicted that the A allele would bind the albumin D-binding protein (DBP), while the G allele could bind the zinc finger protein 161 homolog (ZF5). EMSA experiments (Figure 3C) showed strong binding for the labelled oligonucleotide containing the A allele in the form of two bands. This binding was more efficiently competed by the same unlabelled oligonucleotide than the unlabelled probe containing the $G$ allele. Using consensus competition probes and specific antibodies for DBP and antibodies for two negative controls (OCT-1 and IgG), we confirmed that the top band corresponded to the binding of DBP. For the G allele, EMSA studies suggested potential binding of ZF5 in the form of a third lower band when in the presence of $\mathrm{Zn}^{2+}$ in the binding buffer. Competition was detected when using a specific antibody against ZF5. However, stronger competition 


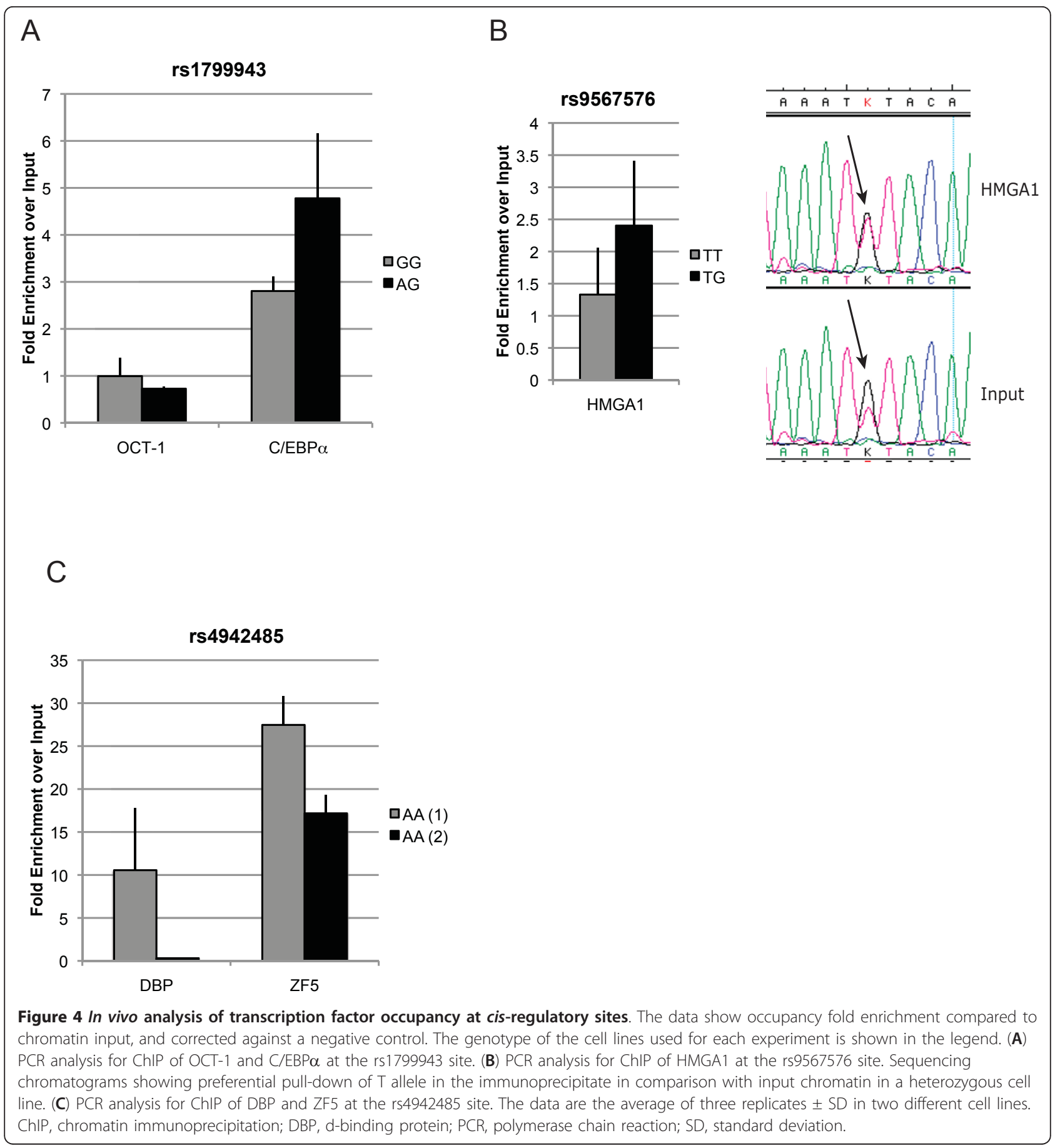

was observed in the same experiment by an antibody against DBP. These data suggest that DBP binding is stronger to the A allele of the rs4942485 sequence, but that possible binding can exist in the presence of the $\mathrm{G}$ allele. Our chromatin immunoprecipitation experiments in this region using specific antibodies support the in vivo occupancy of this site by DBP in MCF-7 cells and ZF5 in both MCF7 and MCF-10A cells (Figure 4C).
Due to the low frequency of this SNP, all cell lines available for these studies were homozygous for the common A allele, preventing us from establishing allele preferences in vivo.

The list of the candidate SNPs for functional analysis as well as information on the gene expression levels of the transcription factors analyzed in this study, are provided as Additional files 10 and 11, respectively. 


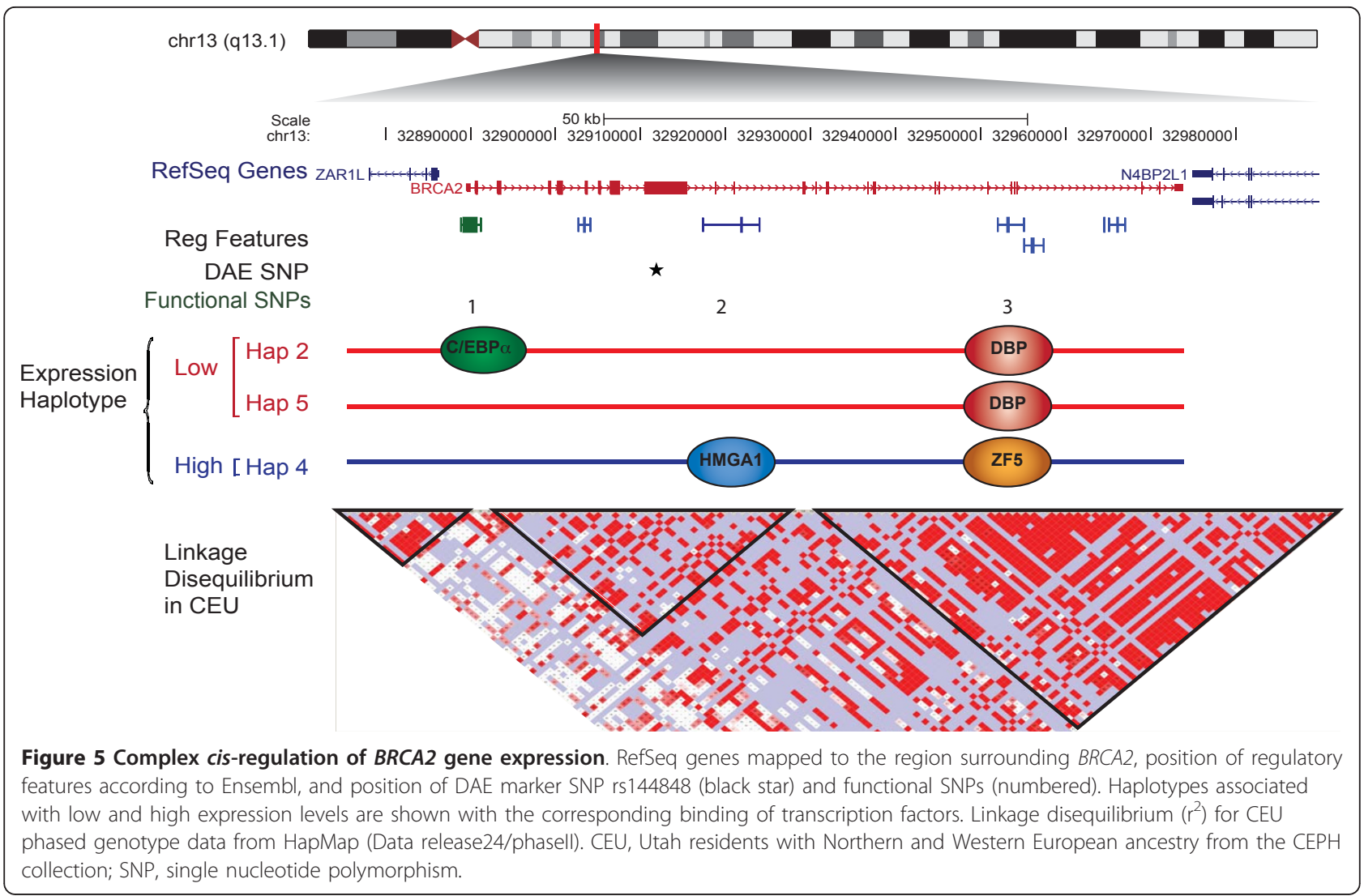

Overall, we identified three SNPs linked to haplotypes 2, 4 and 5, which are located in previously described regulatory elements, have the potential to alter the binding of TFs and are occupied in vivo in breast cancer and normal cell lines (Figure 5). Although rs1799943 is the tag for haplotype 2 and rs9567576 is a tag for haplotypes 2 and 5 , rs 4942485 tags a subset of haplotype 4 (pairwise rs4942485 versus rs4942440 $\mathrm{r}^{2}=0.55$ ), which suggests that further cis-variants might be acting on this haplotype.

\section{Discussion}

The aim of our study was to investigate the effect of regulatory genetic variation of the $B R C A 2$ tumor suppressor gene on disease risk. To this end, we identified haplotypes associated with different expression levels of $B R C A 2$ in normal breast tissue (expression haplotypes) and characterized three cis-acting polymorphisms that alter the binding of transcription factors at regulatory sites. We show that these expression haplotypes have an impact on the expression profile of breast cells. Also, we found some evidence of association between a high expression haplotype and lower risk of developing breast cancer among carriers of germline mutations in BRCA2.

The cells of individuals carrying inactivating germline mutations in the BRCA2 gene rely on the expression of
$B R C A 2$ from the remaining wild-type allele. There is evidence that these cells have a different gene expression profile and ability to repair double-strand DNA breaks compared to cells carrying two wild-type alleles $[21,22]$. We have shown previously that $B R C A 2$ shows differential allelic expression in normal breast tissue. These observations raised the hypothesis that cis-regulatory variation could modify the penetrance of germline mutations in BRCA2, by varying the level of expression of the remaining wild-type allele, if different levels of haploinsufficiency are important. The functional effects of haploinsufficiency at a given locus may vary from tissue to tissue [22]. Many critical biological processes are context specific and the overlap of cis-regulatory variants across different tissues is predicted to be between $10 \%$ to $80 \%$ [43-45], suggesting that the expression haplotypes can vary from tissue to tissue. It is therefore critical to study the relevant tissue when evaluating mechanisms of effect on disease risk. The functional data that we present were obtained from the study of normal breast tissue from control individuals and breast cell lines (normal and cancer).

Haplotypes associated with different levels of gene expression were mapped in unrelated individuals, an approach that has proven powerful to identify cis-acting loci [46]. The difference of expression that we observed 
between the expression haplotypes is small, which suggests that any effect in disease will also be subtle, as expected for common variants. Further functional analysis in breast cells revealed three cis-acting variants affecting the binding of transcription factors which can explain at least in part the differences in expression level associated with the expression haplotypes. These cis-acting variants were mapped to the promoter and two intronic regulatory elements of $B R C A 2$. The regulatory scenario suggested by our findings is complex, with diverse regulatory variants playing a role in different expression haplotypes. The catalogue of genetic variation is improving constantly through studies like the 1000 Genomes Project. The most recent data show more than ten predicted haplotype blocks for the region we studied here. We have analyzed a fraction of the known variation and believe that there may be more cisvariants regulating the expression of $B R C A 2$ in breast tissue, as in others.

In a recent report, Bellacosa and colleagues have shown that $B R C A 2^{+/-}$heterozygous cells have an altered gene expression profile compared with normal cells from individuals without mutations and that this effect is tissue-specific [22]. Even though the expression haplotypes we identified are associated with small differences in the expression of BRCA2 itself, our analyses revealed that the gene expression level of some of the same genes reported by Bellacosa et al. could be correlated with the expression haplotypes. These genes were, unsurprisingly, the ones with the most significant differences in the previous report. These findings suggest that even subtle changes in the expression of BRCA2 can have an impact on the phenotype of normal breast tissue, which can be particularly important when only one expressing allele is present.

In our association study we found some evidence that the minor allele of SNP rs4942440 (corresponding to a high expression haplotype) is associated with a protective effect for the development of breast cancer in mutation carriers. We hypothesize that the higher the expression of $B R C A 2$ from the remaining wild-type allele the better the cells of a mutation carrier individual will carry out DNA repair. The evidence of association in the present study is weak. Mutation phase information for the samples used in the association study was not available. As a consequence, the group of BRCA2 mutation carriers who are heterozygous for this SNP consists of a mixture of individuals who have either the minor or the common allele on the wild type haplotype. We are currently collecting detailed pedigree information and will be able to use phase information in the future, which will strengthen our analysis. Genotyping of additional mutation carriers in the future will further clarify the involvement of this
SNP in the penetrance of $B R C A 2$ mutations in breast cancer. The selection of SNPs for the disease association analysis, as well as the gene expression studies, was performed based on our previous data associating these SNPs/haplotypes with different levels of $B R C A 2$ expression. It is difficult therefore to apply an exact multiple testing, but taken together, the gene expression and association results are suggestive for the involvement of this SNP in breast cancer risk for BRCA2 mutation carriers.

\section{Conclusions}

Our findings support that quite subtle levels of haploinsufficiency of a tumor suppressor gene can have biologically relevant effects. Others have reported similar effects for mutations in the PTEN and TP53 genes in mouse models and APC in Familial Adenomatous Polyposis in humans [47-49]. Common regulatory variation affecting the expression of $A P C$ and TGFBR1 has also been shown to contribute to susceptibility to cancer in humans $[3,4]$. Furthermore, common variants of the $B R C A 1$ wild-type allele have also been recently suggested to modify the risk of breast cancer in BRCA1 mutations carriers [50]. In the future, a confirmation of these findings could be performed by direct measurement of BRCA2 expression levels in mutation carriers and even BRCA2 protein levels. The functional interactions between genetic variability, transcriptional regulation and cancer susceptibility are largely unexplored. Our findings highlight the importance of investigating the regulatory genetic variation of tumour suppressor genes in the search for genetic modifiers of mutation penetrance.

\section{Additional material}

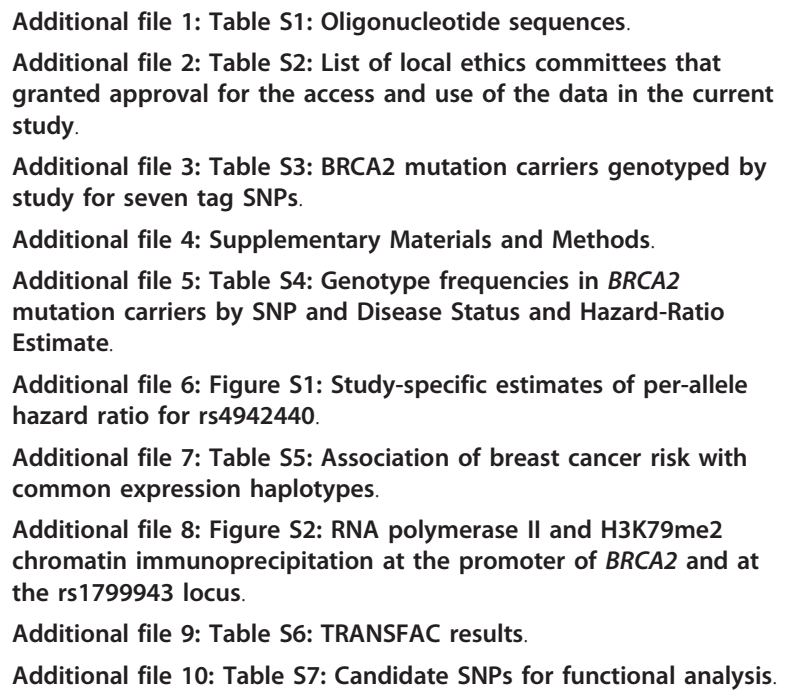
granted approval for the access and use of the data in the current study.

Additional file 3: Table S3: BRCA2 mutation carriers genotyped by study for seven tag SNPs.

Additional file 4: Supplementary Materials and Methods.

Additional file 5: Table S4: Genotype frequencies in BRCA2 mutation carriers by SNP and Disease Status and Hazard-Ratio Estimate.

Additional file 6: Figure S1: Study-specific estimates of per-allele hazard ratio for rs4942440.

Additional file 7: Table S5: Association of breast cancer risk with common expression haplotypes.

Additional file 8: Figure S2: RNA polymerase II and H3K79me2 chromatin immunoprecipitation at the promoter of BRCA2 and at the rs1799943 locus.

Additional file 9: Table S6: TRANSFAC results.

Additional file 10: Table S7: Candidate SNPs for functional analysis. 
Additional file 11: Figure S3: Expression of transcription factors in control normal breast tissue.

\begin{abstract}
Abbreviations
ANOVA: analysis of variance; bp: base pair; CEU: Utah residents with Northern and Western European ancestry from the CEPH collection; ChIP: chromatin immunoprecipitation; Cl: confidence interval; DAE: differential allelic expression; EMSA: electrophoretic mobility shift assay; FCS: fetal calf serum; HR: hazard ratio; LD: linkage disequilibrium; PCR: polymerase chain reaction; SNP: single nucleotide polymorphism; TF: transcription factors.
\end{abstract}

\section{Acknowledgements}

The authors would like to thank the women who contributed samples for this study and Dr R Russell, Dr A Hurtado, Ms R Prathalingam, Dr M Wilson, Dr K Meyer and Dr A Lynch for useful discussion and assistance with methodology, Dr E Dicks for assisting with access to data. We would like to acknowledge the support of the Core Genomics team at Cambridge Research Institute, in particular Mr C Bourne. This work was supported by a Breast Cancer Research Foundation grant to ATM and BAJP; the University of Cambridge, Cancer Research UK, Hutchison Whampoa Limited and NIHR Cambridge Biomedical Research Centre. BAJP is the Li Ka Shing Professor of Oncology at the University of Cambridge. ACA is a Cancer Research - UK Senior Cancer Research Fellow. The CIMBA data management and analysis is supported by Cancer Research - UK.

CIMBA Collaborating Centres

University of Pennsylvania (UPENN): This study was supported by the Breast Cancer Research Foundation; Cancer Genetics Network, Marjorie Cohen Foundation.

Epidemiological study of BRCA1 \& BRCA2 mutation carriers (EMBRACE): Douglas F. Easton is the Principal Investigator of the study. EMBRACE Collaborating Centers are: Coordinating Centre, Cambridge: Susan Peock, Debra Frost, Steve Ellis, Elena Fineberg, Radka Platte. North of Scotland Regional Genetics Service, Aberdeen: Zosia Miedzybrodzka, Helen Gregory. Northern Ireland Regional Genetics Service, Belfast: Patrick Morrison, Lisa Jeffers. West Midlands Regional Clinical Genetics Service, Birmingham: Trevor Cole, Kai-ren Ong, Jonathan Hoffman. South West Regional Genetics Service, Bristol: Alan Donaldson, Margaret James. East Anglian Regional Genetics Service, Cambridge: Joan Paterson, Sarah Downing, Amy Taylor. Medical Genetics Services for Wales, Cardiff: Alexandra Murray, Mark T. Rogers, Emma McCann. St James's Hospital, Dublin \& National Centre for Medical Genetics, Dublin: M. John Kennedy, David Barton. South East of Scotland Regional Genetics Service, Edinburgh: Mary Porteous, Sarah Drummond. Peninsula Clinical Genetics Service, Exeter: Carole Brewer, Emma Kivuva, Anne Searle, Selina Goodman, Kathryn Hill. West of Scotland Regional Genetics Service, Glasgow: Rosemarie Davidson, Victoria Murday, Nicola Bradshaw, Lesley Snadden, Mark Longmuir, Catherine Watt, Sarah Gibson, Eshika Haque, Ed Tobias, Alexis Duncan. South East Thames Regional Genetics Service, Guy's Hospital London: Louise Izatt, Chris Jacobs, Caroline Langman, Anna Whaite. North West Thames Regional Genetics Service, Harrow: Huw Dorkins. Leicestershire Clinical Genetics Service, Leicester: Julian Barwell. Yorkshire Regional Genetics Service, Leeds: Julian Adlard, Carol Chu, Julie Miller. Cheshire \& Merseyside Clinical Genetics Service, Liverpool: Ian Ellis, Catherine Houghton. Manchester Regional Genetics Service, Manchester: D Gareth Evans, Fiona Lalloo, Jane Taylor. North East Thames Regional Genetics Service, NE Thames, London: Lucy Side, Alison Male, Cheryl Berlin. Nottingham Centre for Medical Genetics, Nottingham: Jacqueline Eason, Rebecca Collier. Northern Clinical Genetics Service, Newcastle: Fiona Douglas, Oonagh Claber, Irene Jobson. Oxford Regional Genetics Service, Oxford: Lisa Walker, Diane McLeod, Dorothy Halliday, Sarah Durell, Barbara Stayner. The Institute of Cancer Research and Royal Marsden NHS Foundation Trust: Ros Eeles, Susan Shanley, Nazneen Rahman, Richard Houlston, Elizabeth Bancroft, Lucia D'Mello, Elizabeth Page, Audrey Ardern-Jones, Kelly Kohut, Jennifer Wiggins, Elena Castro, Anita Mitra, Lisa Robertson. North Trent Clinical Genetics Service, Sheffield: Jackie Cook, Oliver Quarrell, Cathryn Bardsley. South West Thames Regional Genetics Service, London: Shirley Hodgson, Sheila Goff, Glen Brice, Lizzie Winchester, Charlotte Eddy, Vishakha Tripathi,
Virginia Attard. Wessex Clinical Genetics Service, Princess Anne Hospital, Southampton: Diana Eccles, Anneke Lucassen, Gillian Crawford, Donna McBride, Sarah Smalley. EMBRACE is supported by Cancer Research UK Grants C1287/A10118 and C1287/A11990. D. Gareth Evans and Fiona Lalloo are supported by an NIHR grant to the Biomedical Research Centre, Manchester. The Investigators at The Institute of Cancer Research and The Royal Marsden NHS Foundation Trust are supported by an NIHR grant to the Biomedical Research Centre at The Institute of Cancer Research and The Royal Marsden NHS Foundation Trust. Ros Eeles, Elizabeth Bancroft and Lucia D'Mello are also supported by Cancer Research UK Grant C5047/A8385. Genetic Modifiers of cancer risk in BRCA1/2 mutation carriers (GEMO): We wish to thank all the GEMO collaborating Cancer Genetics Network 'Groupe Génétique et Cancer' and Fédération Nationale des Centres de Lutte Contre le Cancer, France. The study was supported by the Ligue National Contre le Cancer; Association for International Cancer Research Grant (AICR-07-0454); and the Association "Le cancer du sein, parlons-en!" Award. We wish to thank all the GEMO collaborating groups for their contribution to this study. GEMO Collaborating Centers are: Coordinating Centres, Unité Mixte de Génétique Constitutionnelle des Cancers Fréquents, Centre Hospitalier Universitaire de Lyon/Centre Léon Bérard, \& Equipe «Génétique du cancer du sein», Centre de Recherche en Cancérologie de Lyon: Olga Sinilnikova, Sylvie Mazoyer, Laure Barjhoux, Carole Verny-Pierre, Sophie Giraud, Mélanie Léone; and Service de Génétique Oncologique, Institut Curie, Paris: Dominique Stoppa-Lyonnet, Marion Gauthier-Villars, Bruno Buecher, Claude Houdayer, Virginie Moncoutier, Muriel Belotti, Carole Tirapo, Antoine de Pauw. Institut Gustave Roussy, Villejuif: Brigitte Bressac-de-Paillerets, Audrey Remenieras, Véronique Byrde, Olivier Caron, Gilbert Lenoir. Centre Jean Perrin, Clermont-Ferrand: Yves-Jean Bignon, Nancy Uhrhammer. Centre Léon Bérard, Lyon: Christine Lasset, Valérie Bonadona. Centre François Baclesse, Caen: Agnès Hardouin, Pascaline Berthet. Institut Paoli Calmettes, Marseille: Hagay Sobol, Violaine Bourdon, Tetsuro Noguchi, François Eisinger. Groupe Hospitalier Pitié-Salpétrière, Paris: Florence Coulet, Chrystelle Colas, Florent Soubrier. CHU de Arnaud-de-Villeneuve, Montpellier: Isabelle Coupier, Pascal Pujol. Centre Oscar Lambret, Lille: Jean-Philippe Peyrat, Joëlle Fournier, Françoise Révillion, Philippe Vennin, Claude Adenis. Hôpital René Huguenin/ Institut Curie, St Cloud: Etienne Rouleau, Rosette Lidereau, Liliane Demange, Catherine Nogues. Centre Paul Strauss, Strasbourg: Danièle Muller, JeanPierre Fricker. Institut Bergonié, Bordeaux: Emmanuelle Barouk-Simonet, Françoise Bonnet, Virginie Bubien, Nicolas Sevenet, Michel Longy. Institut Claudius Regaud, Toulouse: Christine Toulas, Rosine Guimbaud, Laurence Gladieff, Viviane Feillel. CHU de Grenoble: Dominique Leroux, Hélène Dreyfus, Christine Rebischung, Magalie Peysselon. CHU de Dijon: Fanny Coron, Laurence Faivre. CHU de St-Etienne: Fabienne Prieur, Marine Lebrun, Caroline Kientz. Hôtel Dieu Centre Hospitalier, Chambéry: Sandra Fert Ferrer Centre Antoine Lacassagne, Nice: Marc Frénay. CHU de Limoges: Laurence Vénat-Bouvet. CHU de Nantes: Capucine Delnatte. CHU Bretonneau, Tours: Isabelle Mortemousque. Creighton University, Omaha, USA: Henry T.Lynch, Carrie L.Snyder.

Helsinki Breast Cancer Study (HBECS): HEBCS would like to thank Dr. Kristiina Aittomäki and Tuomas Heikkinen and research nurse Irja Erkkilä for their help with the patient data and samples. The HEBCS study has been financially supported by the Helsinki University Central Hospital Research Fund, Academy of Finland (132473), the Finnish Cancer Society, and the Sigrid Juselius Foundation.

Mayo Clinic (MAYO): The Mayo Study was supported by NIH grants CA128978 and a Breast Cancer Specialized Program of Research Excellence (SPORE), CA1 16167, the Komen Foundation for the Cure and the Breast Cancer Research Foundation.

Fox Chase Cancer Center (FCCC): A.K.G. was funded by U01CA69631, 5U01CA113916, and the Eileen Stein Jacoby Fund. The author acknowledges support from The University of Kansas Cancer Center and the Kansas Bioscience Authority Eminent Scholar Program. A.K.G. is the Chancellors Distinguished Chair in Biomedical Sciences endowed Professor.

The Pisa Breast Cancer Study (PBCS): We would like to acknowledge the Tumour Tuscany Institute' for a grant (n. AOOGRT/0011780/Q.30.11) to Maria Adelaide Caligo.

The Swedish BRCA1 and BRCA2 Study (SWE-BRCA): Per Karlsson, Margareta Nordling, Annika Bergman and Zakaria Einbeigi, Gothenburg, Sahlgrenska University Hospital; Marie Stenmark-Askmalm and Sigrun Liedgren, Linköping 
University Hospital; Åke Borg, Niklas Loman, Håkan Olsson, Ulf Kristoffersson, Helena Jernström, Katja Harbst and Karin Henriksson, Lund University Hospital; Annika Lindblom, Brita Arver, Anna von Wachenfeldt, Annelie Liljegren, Gisela Barbany-Bustinza and Johanna Rantala, Stockholm, Karolinska University Hospital; Beatrice Melin, Henrik Grönberg, Eva-Lena Stattin and Monica Emanuelsson, Umeå University Hospital; Hans Ehrencrona, Richard Rosenquist Brandell and Niklas Dahl, Uppsala University Hospital. Iceland Landspitali-University Hospital (ILUH): The ILUH group was supported by the Icelandic Association 'Walking for Breast Cancer Research' and by the Landspitali University Hospital Research Fund. Kathleen Cunningham Foundation Consortium for Research into Familial Breast Cancer (kConFab): We wish to thank Heather Thorne, Eveline Niedermayr, all the kConFab research nurses and staff, the heads and staff of the Family Cancer Clinics, and the Clinical Follow Up Study (funded 2001 2009 by NHMRC and currently by the National Breast Cancer Foundation and Cancer Australia \#628333) for their contributions to this resource, and the many families who contribute to kConFab. kConFab is supported by grants from the National Breast Cancer Foundation, the National Health and Medical Research Council (NHMRC) and by the Queensland Cancer Fund, the Cancer Councils of New South Wales, Victoria, Tasmania and South Australia, and the Cancer Foundation of Western Australia.

\section{Author details}

${ }^{1}$ Cambridge Research Institute - CRUK, Li Ka Shing Centre, Cancer Research UK, Robinson Way, Cambridge, CB2 ORE, UK. ${ }^{2}$ Department of Oncology, University of Cambridge, Addenbrooke's Hospital, Robinson Way, Cambridge, CB2 ORE, UK. ${ }^{3}$ Centre for Cancer Genetic Epidemiology, Department of Public Health and Primary Care, University of Cambridge, Worts Causeway, Cambridge CB1 8RN, UK. ${ }^{4}$ Department of Medicine, Hematology-Oncology, Abramson Cancer Center, University of Pennsylvania, 3400 Spruce St, Philadelphia, PA 19104, USA. ${ }^{5}$ Genetic Medicine, Manchester Academic Health Sciences Centre, Central Manchester University Hospitals NHS Foundation Trust, Brunswick Street, Manchester, M13 9PL, UK. ${ }^{6}$ Oncogenetics Team, The Institute of Cancer Research and Royal Marsden NHS Foundation Trust, 15 Cotswold Rd, Belmont, Sutton Surrey SM2 5NG, UK. ${ }^{7}$ Clinical Genetics, Guy's and St. Thomas' NHS Foundation Trust, 7th floor, Borough Wing, Guy's Hospital, Great Maze Pond, London SE1 9RT, UK. ${ }^{8}$ Yorkshire Regional Genetics Service, Ward 10, 3rd Floor, Chapel Allerton Hospital Chapeltown Road, Leeds, LS7 4SA, UK. 'Wessex Clinical Genetics Service, Princess Anne Hospital, Coxford Road, Southampton, SO16 5YA, UK. ${ }^{10}$ GEMO Study Collaborators: Cancer Genetics Network "Groupe Génétique et Cancer", Fédération Nationale des Centres de Lutte Contre le Cancer, France. ${ }^{11}$ INSERM U1052, CNRS UMR5286, Université Lyon 1, Cancer Research Center of Lyon, Lyon, 7 rue Guillaume Paradin, 69008 Lyon, France. ${ }^{12}$ Unité Mixte de Génétique Constitutionnelle des Cancers Fréquents, Centre Hospitalier Universitaire de Lyon/Centre Léon Bérard, 28 rue Laennec, 69008 Lyon, France. ${ }^{13}$ Service de Génétique Oncologique, Institut Curie, 26 rue d'UIm 75248 Paris cedex 05, France. ${ }^{14}$ Unité INSERM U830, Institut Curie, 26 rue d'Ulm 75248 Paris cedex 05, France. ${ }^{15}$ Université Paris Descartes, Faculté de Médecine, 12, rue de l'Ecole de Médecine 75270 Paris Cedex 06, France. ${ }^{16}$ Centre de Génétique, CHU Dijon, Université de Bourgogne, Dijon F-21000, France. ${ }^{17}$ Centre Georges François Leclerc, 1 Rue Professeur Marion 21000 Dijon, France. ${ }^{18}$ Department of Medical Oncology, Centre Hospitalier Universitaire Dupuytren, Limoges, France. ${ }^{19} \mathrm{Centre}$ René Gauducheau, Boulevard Jacques Monod 44805 St Herblain Cedex, Nantes, France. ${ }^{20}$ Department of Obstetrics and Gynecology, Helsinki University Central Hospital, P.O. BOX 700, 00029 HUS, Finland. ${ }^{21}$ Department of Laboratory Medicine and Pathology, Mayo Clinic, 200 1st Street Southwest Rochester, MN 55905, USA. ${ }^{22}$ University of Kansas Medical Center, 3901 Rainbow Boulevard, KS City, KS 66160, USA. ${ }^{23}$ Division of Surgical, Molecular and Ultrastructural Pathology, Department of Oncology, University of Pisa and Pisa University Hospital, Lungarno Antonio Pacinotti, 4356126 Pisa, Italy. ${ }^{24}$ Department of Pathology, Landspitali University Hospital, Reykjavik 101, Iceland. ${ }^{25}$ Faculty of Medicine, University of Iceland, Vatnsmýrarvegur 16, level 4 Reykjavik, Iceland. ${ }^{26}$ Peter MacCallum Cancer Institute, Locked Bag 1, A'Beckett Street, Melbourne, VIC 8006, Australia. ${ }^{27}$ Queensland Institute of Medical Research, 300 Herston Road, Herston, Brisbane, QLD 4006, Australia. ${ }^{28}$ Cambridge Experimental Cancer Medicine Centre, Li Ka Shing Centre, Robinson Way, Cambridge, CB2 ORE, UK. ${ }^{29}$ Institute for Biotechnology and Bioengineering, Centre for Molecular and Structural Biomedicine, Department of Biomedical Sciences and Medicine, University of Algarve,
Portugal. ${ }^{30}$ Institute for Biotechnology and Bioengineering, Centre for Molecular and Structural Biomedicine, Department of Biomedical Sciences and Medicine, Gambelas Campus, Building 7, University of Algarve, 8005-139 Faro, Portugal.

\section{Authors' contributions}

The project was conceived by ATM and BAJP. Functional analysis was performed by ATM and MOR. Gene expression experiments were conceived, performed and analyzed by ATM, SFC, MD, CNC and CC. The study of CIMBA carriers was coordinated by GC-T. The CIMBA data management is coordinated by ACA and LM. Genotyping of CIMBA carriers was performed by GC-T and OMS. Patient DNA material and clinical data of carriers was provided by SMD, EMBRACE, DFE, SP, DF, DGE, RE, LI, JA, DE, GEMO, OMS, SM, DSL, MGV, LF, LVB, CD, HN, FJC, AKG, MAC, SWE-BRCA, RBB, KConFab, $X C, J B, S H$ and GCT. Data were analyzed by ATM, ACA, SS, MD, CK and CNC. The manuscript was drafted by ATM, ACA and BAJP. All authors read, critically revised and approved the final manuscript.

\section{Competing interests}

The authors declare that they have no conflicts of interest.

Received: 12 August 2011 Revised: 30 January 2012

Accepted: 18 April 2012 Published: 18 April 2012

\section{References}

1. Morley M, Molony CM, Weber TM, Devlin JL, Ewens KG, Spielman RS, Cheung VG: Genetic analysis of genome-wide variation in human gene expression. Nature 2004, 430:743-747.

2. Lo H, Wang Z, Hu Y, Yang H, Gere S, Buetow K, Lee M: Allelic variation in gene expression is common in the human genome. Genome Res 2003, 13:1855-1862.

3. Valle L, Serena-Acedo T, Liyanarachchi S, Hampel H, Comeras I, Li Z, Zeng Q, Zhang H-T, Pennison MJ, Sadim M, Pasche B, Tanner SM, de la Chapelle A: Germline allele-specific expression of TGFBR1 confers an increased risk of colorectal cancer. Science 2008, 321:1361-1365.

4. Yan H, Dobbie Z, Gruber S, Markowitz S, Romans K, Giardiello F, Kinzler K, Vogelstein B: Small changes in expression affect predisposition to tumorigenesis. Nat Genet 2002, 30:25-26.

5. Tan AC, Fan J-B, Karikari C, Bibikova M, Garcia EW, Zhou L, Barker D, Serre D, Feldmann G, Hruban RH, Klein AP, Goggins M, Couch FJ, Hudson TJ, Winslow RL, Maitra A, Chakravarti A: Allele-specific expression in the germline of patients with familial pancreatic cancer: an unbiased approach to cancer gene discovery. Cancer Biol Ther 2008, 7:135-144.

6. Shen J, Medico L, Zhao HW: Allelic imbalance in BRCA1 and BRCA2 gene expression and familial ovarian cancer. Cancer Epidemiol Biomarkers Prev 2010, 20:50-56.

7. Azzato EM, Lee AJX, Teschendorff A, Ponder BAJ, Pharoah P, Caldas C, Maia AT: Common germ-line polymorphism of C1QA and breast cancer survival. Br J Cancer 2010, 102:1294-1298.

8. Chen X, Weaver J, Bove B, Vanderveer L, Weil S, Miron A, Daly M, Godwin A: Allelic imbalance in BRCA1 and BRCA2 gene expression is associated with an Increased breast cancer risk. Hum Mol Genet 2008, 17:1336-1348.

9. Meyer K, Maia AT, O'Reilly M, Teschendorff A, Chin S, Caldas C, Ponder B: Allele-specific up-regulation of FGFR2 increases susceptibility to breast cancer. PLOS Biol 2008, 6:e108.

10. Dunning AM, Healey CS, Baynes C, Maia AT, Scollen S, Vega A, Rodríguez R, Barbosa-Morais NL, Ponder BA, for S, Low YL, Bingham S, for E, Haiman CA, Le Marchand L, for MEC, Broeks A, Schmidt MK, for A, Hopper J, Southey M, for A, Beckmann MW, Fasching PA, for B, Peto J, Johnson N, for B, Bojesen SE, Nordestgaard B, et al: Association of ESR1 gene tagging SNPs with breast cancer risk. Hum Mol Genetics 2009, 18:1131-1139.

11. Ware MD, DeSilva D, Sinilnikova OM, Stoppa-Lyonnet D, Tavtigian SV, Mazoyer S: Does nonsense-mediated mRNA decay explain the ovarian cancer cluster region of the BRCA2 gene? Oncogene 2006, 25:323-328.

12. Schmidt D, Wilson MD, Ballester B, Schwalie PC, Brown GD, Marshall A, Kutter C, Watt S, Martinez-Jimenez CP, Mackay S, Talianidis I, Flicek P, Odom DT: Five-vertebrate ChIP-seq reveals the evolutionary dynamics of transcription factor binding. Science 2010, 328:1036-1040.

13. Pomerantz MM, Ahmadiyeh N, Jia L, Herman P, Verzi MP, Doddapaneni H, Beckwith CA, Chan JA, Hills A, Davis M, Yao K, Kehoe SM, Lenz HJ, Haiman CA, Yan C, Henderson BE, Frenkel B, Barretina J, Bass A, Tabernero J, 
Baselga J, Regan MM, Manak JR, Shivdasani R, Coetzee GA, Freedman ML: The 8q24 cancer risk variant rs6983267 shows long-range interaction with MYC in colorectal cancer. Nat Genet 2009, 41:882-884.

14. Maia AT, Spiteri I, Lee AJ, O'Reilly M, Jones L, Caldas C, Ponder BA: Extent of differential allelic expression of candidate breast cancer genes is similar in blood and breast. Breast Cancer Res 2009, 11:R88.

15. Begg CB, Haile RW, Borg A, Malone KE, Concannon P, Thomas DC, Langholz B, Bernstein L, Olsen JH, Lynch CF, Anton-Culver H, Capanu M, Liang X, Hummer AJ, Sima C, Bernstein JL: Variation of breast cancer risk among BRCA1/2 carriers. JAMA 2008, 299:194-201.

16. Antoniou A, Pharoah PDP, Narod S, Risch HA, Eyfjord JE, Hopper JL, Loman N, Olsson H, Johannsson O, Borg A, Pasini B, Radice P, Manoukian S, Eccles DM, Tang N, Olah E, Anton-Culver H, Warner E, Lubinski J, Gronwald J, Gorski B, Tulinius H, Thorlacius S, Eerola H, Nevanlinna H, Syrjäkoski K, Kallioniemi O-P, Thompson D, Evans C, Peto J, et al: Average risks of breast and ovarian cancer associated with BRCA1 or BRCA2 mutations detected in case series unselected for family history: a combined analysis of 22 studies. Am J Hum Genet 2003, 72:1117-1130.

17. Rebbeck TR: Inherited predisposition and breast cancer: modifiers of BRCA1/2-associated breast cancer risk. Environ Mol Mutagen 2002, 39:228-234.

18. Antoniou $A C$, Sinilnikova $O M$, Simard J, Léoné $M$, Dumont $M$, Neuhausen SL, Struewing JP, Stoppa-Lyonnet D, Barjhoux L, Hughes DJ, Coupier I, Belotti M, Lasset C, Bonadona V, Bignon Y-J, Rebbeck TR, Wagner T, Lynch HT, Domchek SM, Nathanson KL, Garber JE, Weitzel J, Narod SA, Tomlinson G, Olopade Ol, Godwin A, Isaacs C, Jakubowska A, Lubinski J, et al: RAD51 135G-> C modifies breast cancer risk among BRCA2 mutation carriers: results from a combined analysis of 19 studies. Am J Hum Genet 2007, 81:1186-1200.

19. Antoniou AC, Spurdle AB, Sinilnikova OM, Healey S, Pooley KA, Schmutzler RK, Versmold B, Engel C, Meindl A, Arnold N, Hofmann W, Sutter C, Niederacher D, Deissler H, Caldes T, Kämpjärvi K, Nevanlinna H, Simard J, Beesley J, Chen X, Neuhausen SL, Rebbeck TR, Wagner T, Lynch HT, Isaacs C, Weitzel J, Ganz PA, Daly MB, Tomlinson G, et al: Common breast cancer-predisposition alleles are associated with breast cancer risk in BRCA1 and BRCA2 mutation carriers. Am J Hum Genet 2008, 82:937-948.

20. Antoniou AC, Beesley J, McGuffog L, Sinilnikova OM, Healey S, Neuhausen SL, Ding YC, Rebbeck TR, Weitzel JN, Lynch HT, Isaacs C, Ganz PA, Tomlinson G, Olopade OI, Couch FJ, Wang X, Lindor NM, Pankratz VS, Radice P, Manoukian S, Peissel B, Zaffaroni D, Barile M, Viel A, Allavena A, Dall'olio V, Peterlongo P, Szabo Cl, Zikan M, Claes K, et al: Common breast cancer susceptibility alleles and the risk of breast cancer for BRCA1 and BRCA2 mutation carriers: implications for risk prediction. Cancer Res 2010, 70:9742-9754.

21. Arnold K, Kim M-K, Frerk K, Edler L, Savelyeva L, Schmezer P, Wiedemeyer R: Lower level of BRCA2 protein in heterozygous mutation carriers is correlated with an increase in DNA double strand breaks and an impaired DSB repair. Cancer Lett 2006, 243:90-100.

22. Bellacosa A, Godwin AK, Peri S, Devarajan K, Caretti E, Vanderveer L, Bove B, Slater C, Zhou Y, Daly M, Howard S, Campbell KS, Nicolas E, Yeung AT, Clapper ML, Crowell JA, Lynch HT, Ross E, Kopelovich L, Knudson AG: Altered gene expression in morphologically normal epithelial cells from heterozygous carriers of BRCA1 or BRCA2 mutations. Cancer Prev Res (Phila) 2010, 3:48-61.

23. The International HapMap Consortium: A haplotype map of the human genome. Nature 2005, 437:1299-1320.

24. Consortium TGP: A map of human genome variation from populationscale sequencing. Nature 2010, 467:1061-1073.

25. The 1000 Genomes Consortium. [http://www.1000genomes.org/].

26. The International HapMap Project. [http://hapmap.ncbi.nlm.nih.gov].

27. Barrett JC, Fry B, Maller J, Daly MJ: Haploview: analysis and visualization of LD and haplotype maps. Bioinformatics 2005, 21:263-265.

28. Haploview. [http://www.broad.mit.edu/mpg/haploview].

29. Whitehead RH, Bertoncello I, Webber LM, Pedersen JS: A new human breast carcinoma cell line (PMC42) with stem cell characteristics. I. Morphologic characterization. J Natl Cancer Inst 1983, 70:649-661.

30. Soule HD, Vazguez J, Long A, Albert S, Brennan M: A human cell line from a pleural effusion derived from a breast carcinoma. J Natl Cancer Inst 1973, 51:1409-1416.
31. Flanagan L, Van Weelden K, Ammerman C, Ethier SP, Welsh J: SUM-159PT cells: a novel estrogen independent human breast cancer model system. Breast Cancer Res Treat 1999, 58:193-204.

32. Soule HD, Maloney TM, Wolman SR, Peterson WD, Brenz R, McGrath CM, Russo J, Pauley RJ, Jones RF, Brooks SC: Isolation and characterization of a spontaneously immortalized human breast epithelial cell line, MCF-10. Cancer Res 1990, 50:6075-6086.

33. Carvalho B, Bengtsson H, Speed TP, Irizarry RA: Exploration, normalization, and genotype calls of high-density oligonucleotide SNP array data. Biostatistics 2007, 8:485-499

34. R Development Core Team: In R: a language and environment for statistical computing Edited by: Team RDC 2010.

35. Wingender E: The TRANSFAC project as an example of framework technology that supports the analysis of genomic regulation. Brief Bioinform 2008, 9:326-332.

36. Schmidt D, Schwalie PC, Ross-Innes CS, Hurtado A, Brown GD, Carroll JS, Flicek P, Odom DT: A CTCF-independent role for cohesin in tissuespecific transcription. Genome Res 2010, 20:578-588.

37. Dunning MJ, Smith ML, Ritchie ME, Tavaré S: Beadarray: R classes and methods for Illumina bead-based data. Bioinformatics 2007, 23:2183-2184

38. Cairns JM, Dunning MJ, Ritchie ME, Russell R, Lynch AG: BASH: a tool for managing BeadArray spatial artefacts. Bioinformatics 2008, 24:2921-2922.

39. Antoniou A, Sinilnikova O, McGuffog L, Healey S, Nevanlinna H, Heikkinen T, Simard J, Spurdle A, Beesley J, Chen X, Neuhausen S, Ding Y, Couch F, Wang X, Fredericksen Z, Peterlongo P, Peissel B, Bonanni B, Viel A, Bernard L, Radice P, Szabo C, Foretova L, Zikan M, Claes K, Greene M, Mai P, Rennert G, Lejbkowicz F, et al: Common variants in LSP1, 2q35 and 8q24 and breast cancer risk for BRCA1 and BRCA2 mutation carriers. Hum Mol Genet 2009, 18:4442-4456.

40. Lange K, Weeks D, Boehnke M: Programs for Pedigree Analysis: MENDEL, FISHER, and dGENE. Genet Epidemiol 1988, 5:471-472.

41. Lin DY, Zeng D, Millikan R: Maximum likelihood estimation of haplotype effects and haplotype-environment interactions in association studies. Genet Epidemiol 2005, 29:299-312.

42. Guenther MG, Levine SS, Boyer LA, Jaenisch R, Young RA: A chromatin landmark and transcription initiation at most promoters in human cells. Cell 2007, 130:77-88.

43. Campbell C, Kirby A, Nemesh J, Daly M, Hirschhorn J: A survey of allelic imbalance in F1 mice. Genome Res 2008, 18:555-563.

44. Dimas AS, Deutsch S, Stranger BE, Montgomery SB, Borel C, Attar-Cohen H, Ingle C, Beazley C, Gutierrez Arcelus M, Sekowska M, Gagnebin M, Nisbett J, Deloukas P, Dermitzakis ET, Antonarakis SE: Common regulatory variation impacts gene expression in a cell type-dependent manner. Science 2009, 325:1246-1250.

45. Emilsson V, Thorleifsson $G$, Zhang B, Leonardson AS, Zink F, Zhu J, Carlson S, Helgason A, Walters GB, Gunnarsdottir S, Mouy M, Steinthorsdottir V, Eiriksdottir GH, Bjornsdottir G, Reynisdottir I, Gudbjartsson D, Helgadottir A, Jonasdottir A, Jonasdottir A, Styrkarsdottir U, Gretarsdottir S, Magnusson KP, Stefansson H, Fossdal R, Kristjansson K, Gislason HG, Stefansson T, Leifsson BG, Thorsteinsdottir U, Lamb JR, et al: Genetics of gene expression and its effect on disease. Nature 2008, 452:423-428.

46. Pastinen T, Ge B, Gurd S, Gaudin T, Dore C, Lemire M, Lepage P, Harmsen E, Hudson TJ: Mapping common regulatory variants to human haplotypes. Hum Mol Genet 2005, 14:3963-3971.

47. Alimonti A, Carracedo A, Clohessy JG, Trotman LC, Nardella C, Egia A, Salmena L, Sampieri K, Haveman WJ, Brogi E, Richardson AL, Zhang J, Pandolfi PP: Subtle variations in Pten dose determine cancer susceptibility. Nat Genet 2010, 42:454-458.

48. Venkatachalam S, Shi YP, Jones SN, Vogel H, Bradley A, Pinkel D, Donehower LA: Retention of wild-type p53 in tumors from p53 heterozygous mice: reduction of $\mathrm{p} 53$ dosage can promote cancer formation. EMBO J 1998, 17:4657-4667.

49. Yeung AT, Patel BB, Li X-M, Seeholzer SH, Coudry RA, Cooper HS, Bellacosa A, Boman BM, Zhang T, Litwin S, Ross EA, Conrad P, Crowell JA, Kopelovich L, Knudson A: One-hit effects in cancer: altered proteome of morphologically normal colon crypts in familial adenomatous polyposis. Cancer Res 2008, 68:7579-7586.

50. Matys V, Kel-Margoulis OV, Fricke E, Liebich I, Land S, Barre-Dirrie A, Reuter I, Chekmenev D, Krull M, Hornischer K, Voss N, Stegmaier P, Lewicki- 
Potapov B, Saxel H, Kel AE, Wingender E: TRANSFAC and its module TRANSCompel: transcriptional gene regulation in eukaryotes. Nucleic Acids Res 2006, 34:D108-110.

doi:10.1186/bcr3169

Cite this article as: Maia et al:: Effects of BRCA2 cis-regulation in normal breast and cancer risk amongst BRCA2 mutation carriers. Breast Cancer Research 2012 14:R63.

Submit your next manuscript to BioMed Central and take full advantage of:

- Convenient online submission

- Thorough peer review

- No space constraints or color figure charges

- Immediate publication on acceptance

- Inclusion in PubMed, CAS, Scopus and Google Scholar

- Research which is freely available for redistribution

Submit your manuscript at www.biomedcentral.com/submit 